\title{
EFEITOS DE PROJETOS PEDAGÓGICOS E/OU DE INTERVENÇÕES SOCIOAMBIENTAL E DA REPLICABILIDADE NA FORMAÇÃO DE AGENTES MULTIPLICADORES EM CAPACITAÇÕES DE CURTA DURAÇÃO EM EDUCAÇÃO AMBIENTAL
}

José Ricardo Barbosa da Silva ${ }^{1}$ Ângela Maria Cirilo² Alexandre Arthur de Sena Santos ${ }^{3}$ Raul José de Almeida Pires Falcão ${ }^{4}$

Resumo: Este relato de experiência tem como objetivo demonstrar a efetiva formação de agentes multiplicadores, em Educação Ambiental e intervenção socioambiental, proporcionada pela geração de projetos pedagógicos e/ou socioambientais em capacitação de curta duração e as principais possibilidades avaliativas que o indicador Replicabilidade pode proporcionar no Projeto Pedagogia Ambiental de Suape (PPA). Foi considerado o universo amostral de 61 turmas dessas capacitações, 1206 alunos concluintes e 500 alunos entrevistados $(41,4 \%)$. As informações levantadas podem ser utilizadas como diretrizes para o planejamento pedagógico do PPA de Suape, bem como a Replicabilidade e os projetos elaborados nas capacitações podem ser utilizadas como modelos de avaliação e de promoção de agentes multiplicadores em outros projetos de Educação Ambiental.

Palavras-chave: Meio Ambiente; Ambiente e Sociedade; Cursos e Oficinas; Avaliação e Monitoramento.

\footnotetext{
${ }^{1}$ SUAPE - Complexo Industrial Portuário Governador Eraldo Gueiros.

E-mail: ricardosilva@suape.pe.gov.br. Link para o Lattes: http://lattes.cnpq.br/0628684476771345

2 Instituto Monã. E-mail: anjoca67@gmail.com. Link para o Lattes: http://lattes.cnpq.br/3222381535306104

3 Instituto Monã. E-mail: arthurssena@gmail.com.

Link para o Lattes: http://lattes.cnpq.br/7485404244886455

4 Instituto Monã. E-mail: raulfalcao25@gmail.com.
}

revista brasileira 
Abstract: This experience report aims to demonstrate the effective training of multiplying agents, in Environmental Education and socioenvironmental intervention, provided by the generation of educational and/or socioenvironmental projects in short-term training and the main evaluative possibilities that the Replicabilidade indicator can provide in the Projeto Pedagogia Ambiental de Suape (PPA). For this, the total sample universe of: 61 classes of these training, 1206 graduating students and 500 interviewed students $(41.4 \%)$ was considered. The information gathered can be used as guidelines for the pedagogical planning of the Suape's PPA, as well as the Replicabilidade and the projects elaborated in the training sessions can be used as models of evaluation and promotion of multiplying agents in other Environmental Education projects.

Keywords: Environment; Environment and Society; Courses and Workshops; Evaluation and Monitoring.

\section{Introdução}

Em 2010 foi criado o Programa de Educação Ambiental de Suape (PEA), que contém, entre outros projetos, o Projeto Pedagogia Ambiental de Suape (PPA), ambos frutos dos Projetos Básicos Ambientais do EIA/RIMA Suape 2000, que foi elaborado e aprovado para os licenciamentos ambientais alusivos à ampliação e modernização do Porto de Suape (Ipojuca Pernambuco - Brasil) que ocorreram na década de 2000.

Durante mais de uma década de execução (desde 2011), o PPA da empresa Suape vem realizando capacitações de Educação Ambiental (cursos e oficinas de curta duração) que já tiveram 4.388 alunos concluintes, distribuídos em sete capacitações diferentes (duas que não são atualmente executadas).

Desde a elaboração do PPA de Suape (em 2010), houve a contemplação e execução de um subprojeto denominado Avaliação $e$ Monitoramento, com o intuito de monitorar, avaliar, corrigir, ampliar e voltar a monitorar e avaliar, reiniciando assim esse ciclo. Possui como um dos instrumentos utilizados o indicador Replicabilidade (dentre outros), que por sua vez, tem como principal objetivo evidenciar desdobramentos sobre a execução de projetos pedagógicos e/ou de intervenções socioambientais elaborados pelos alunos durante as capacitações do PPA. De forma objetiva, a Replicabilidade é um índice que demonstra efetivamente o nível de alcance das capacitações do PPA de Suape na formação de agentes ambientais efetivos.

Essa ferramenta, juntamente com os demais indicadores, tem possibilitado avaliações objetivas quanto algumas metodologias pedagógicas, diversificação de temas abordados nas capacitações, verificações sobre o objetivo de mudança de conduta que a Educação Ambiental pode proporcionar e outros aperfeiçoamentos no PPA de Suape. 
Portanto, este trabalho tem como objetivo verificar a experiência das práticas ambientais realizadas pelos alunos nas capacitações do Projeto Pedagogia Ambiental de Suape e o uso do mecanismo da Replicabilidade na avaliação na formação de agentes ambientais multiplicadores, como proposta que pode ser reproduzida em outros projetos de Educação Ambiental.

\section{Descrição do cenário e das capacitações realizadas em Suape}

\section{Suape: uma empresa pública com história controversa e ambiente e cenário inusitados}

A empresa Suape - Complexo Industrial Portuário Governador Eraldo Gueiros ou simplesmente Suape, indubitavelmente é uma das mais importantes instituições públicas do estado de Pernambuco, seja pela sua importância econômica ou por sua relevância socioambiental.

Para entender a importância de Suape, faz-se necessário considerar o histórico dessa Empresa, desde a formação do seu território, antes mesmo da criação de Suape e considerar sua complexidade como Instituição.

Nesse contexto e, considerando uma maneira didática de apresentar Suape, foi escolhido inicialmente descrever a Empresa e, em seguida, contextualizar o histórico geral da região onde a Empresa está situada. Concomitante e inevitavelmente a complexidade de Suape será revelada ao longo da explanação. Diante disso, será realizada uma caracterização objetiva e clara sobre a Empresa.

A idealização e a forma dos primeiros passos profissionais para a criação do Porto de Suape surgiram em meados do século XX, principalmente concentrados na figura do padre francês da Ordem Dominicana, Louis-Joseph Lebret, que idealizou e investiu esforços para a realização de estudos técnicos sobre a viabilidade do empreendimento (CAVALCANTI; GODOY; ROCHA, 2018, p. 38), tendo a sua criação concretizada somente em 1978 (PERNAMBUCO, 1978).

Mesmo sendo um porto jovem em comparação com outros no Brasil, já são mais de 4 décadas de história e transformações, que Cavalcanti, Godoy e Rocha (2018, p. 43) classificam de forma simplista essa história em três períodos: concepção/início e estagnação, entre 1960 e 2004; aceleração econômica, entre 2005 e 2012; desmobilização/crise, a partir de 2012. Notoriamente essa classificação temporal é puramente do ponto de vista econômico, mas para a formação de marcos históricos sólidos, uma visão mais holística se faz necessária. Então, alguns acontecimentos que mudaram Suape ou que mudaram o mundo ao longo desses 41 anos precisam ser pontuados:

a) O primeiro Plano Diretor de Suape foi criado em 1975 e sua mais recente atualização data de 2010, com vigência entre 2011 e 2030 (SUAPE, 2011, p. 11); 
b) Em 2000 foi iniciado processo de modernização e ampliação do porto de Suape (Disponível em: http://www.suape.pe.gov.br/pt/institucional/historico-de-suape, acessado em: 13 de abril de 2020.);

c) A legislação ambiental evoluiu em todo o mundo, como aconteceu no Brasil (SÁNCHEZ, 2013, p. 62). Essa evolução não foi somente no sentido de aprimoramento, mas também de rigorosidade. Esse fato somado à modernização do Porto, fez com que fosse necessária a execução da Avaliação de Impacto Ambiental (AIA) por meio do Estudo de Impacto Ambiental (EIA) e seu respectivo Relatório de Impacto de Meio Ambiente (RIMA). Isso gerou a elaboração do Projeto Básico de Ampliação e Modernização do Porto de Suape - Volume V - Projeto Básico Ambiental, contendo 20 Programas Ambientais, que na verdade são os compromissos ou passivos ambientais gerados e aprovados para os investimentos estruturais que foram realizados nos anos seguintes. Dentre os Programas Ambientais, há o PBA 17 - Programa de Educação Ambiental, que tem a finalidade de disponibilizar capacitações na temática ambiental para a população do Território Estratégico de Suape, composto por oito municípios que circundam Suape (Cabo de Santo Agostinho, Escada, Ipojuca, Jaboatão dos Guararapes, Moreno, Ribeirão, Rio Formoso e Sirinhaém) (PIRES ADVOGADOS \& CONSULTORES S/C, 2000a);

d) No início da década de 2010 surge uma forte crise econômica gerada por uma crise política no Brasil, que somada ao período de desmobilização já previsto após as obras estruturais do Porto e de empresas que tinham se estabelecido no território de Suape, promoveu um severo marco econômico negativo na região de Suape (CAVALCANTI; GODOY; ROCHA, 2018, p. 38). Porém, esse importante fato da história recente do Brasil não foi motivo para a empresa Suape ter severos impactos em sua atividade portuária, como pode ser observado nos dados disponibilizados pela Agência Nacional de Transporte Aquaviário (ANTAQ, 2020, disponível em: http://web.antaq.gov.br/ANUARIO/).

De forma objetiva, pode-se afirmar que atualmente Suape é uma empresa pública de direito privado, com capital $100 \%$ do governo do estado de Pernambuco, que tem como atividades principais a atividade portuária e a capitação de empresas dentro do seu extenso território. Possui uma área estimada em 13.500 ha, parte no município do Cabo de Santo Agostinho e parte no município de Ipojuca, em Pernambuco, Nordeste do Brasil, formado por um mosaico de solos do ponto de vista geológico, vegetações, usos e ocupações do solo, situações socioambientais e finalidades para o uso territorial (PERNAMBUCO, 2011). 
É valido acrescentar que esse território foi composto por áreas de 26 engenhos de cana-de-açúcar, que ainda hoje trazem resquícios do desmatamento provocado pela monocultura sucroalcooleira construída a partir de trabalho escravo originalmente e com diversos conflitos socioambientais que ainda se perpetuam até hoje, pelo menos em parte (PIRES ADVOGADOS \& CONSULTORES S/C, 2000b).

Por causa dessa magnitude territorial, complexidade industrial e diversidade natural e antrópica, Suape possui um território dividido em Zonas e Setores, conforme o art. 13을 do Decreto № 37.160/2011, que são: Zona Industrial Portuária - ZIP (14\% da área total); Zona Industrial - ZI (22\%); Zona Central de Serviços - ZCS (3\%); Setor Especial de Habitação de Interesse Social - SEHIS; Zona de Preservação Ecológica - ZPEC (59\%); Setor Especial Ambiental - SEA; Zona de Preservação Cultural - ZPC; Setor de Proteção Cultural - SPC (CAVALCANTI; GODOY; ROCHA, 2018, p. 38; PERNAMBUCO, 2011, p. 40)

Diante disso, os diversos e marcantes conflitos socioambientais dentro do território de Suape, conforme demonstra Souza (2018, p. 133), somados aos elementos já expostos e em particular a ampliação e modernização do Porto, fazem com que a Empresa Suape tenha diversos passivos ambientais. Dentre esses passivos, será destacado à frente o Programa de Educação Ambiental de Suape (PEA), que compreende o Projeto Pedagogia Ambiental de Suape (PPA).

\section{Cursos e Oficinas de Suape como proposta de mudanças de paradigmas}

Como já mencionado, para a obtenção das devidas licenças ambientais necessárias para a ampliação e modernização do Porto de Suape nos anos 2000, uma série de compromissos ambientais foram formalizados, dentre esses o PBA - 17 - Programa de Educação Ambiental de Suape (PEA), que por sua vez é formado por quatro projetos dos quais um aqui é destacado: Projeto Pedagogia Ambiental de Suape (PPA).

Para garantir a execução do PPA Suape está fazendo essa compensação ambiental numa dimensão estadual, com capacitações de recursos humanos implantados a partir de 2010, como parte do PPA de Suape. Tais capacitações foram ofertadas no formato de cursos e oficinas, desde então, com diversas revisões, modificações, inovações de temas e metodologias ao longo da última década.

Atualmente são oferecidos quatro cursos e uma oficina, que possuem diversas semelhanças, mas objetivamente são voltados para públicos diferentes. A Tabela 1 apresenta as cinco capacitações e suas especificações. 
Tabela 1: Especificações dos cursos e oficina ofertados no Projeto Pedagogia Ambiental de Suape.

\begin{tabular}{|c|c|c|}
\hline Capacitação & Objetivo & $\begin{array}{l}\text { Público-alvo } \\
\end{array}$ \\
\hline $\begin{array}{l}\text { C1-Curso } \\
\text { Livre de } \\
\text { Educação } \\
\text { Ambiental }\end{array}$ & $\begin{array}{l}\text { Sensibilizar atores sociais } \\
\text { para discutirem e difundirem } \\
\text { ideias e ações de } \\
\text { sustentabilidade, usando } \\
\text { como ferramenta os } \\
\text { "Conceitos Básicos para se } \\
\text { fazer Educação Ambiental do } \\
\text { Programa das Nações } \\
\text { Unidas para o Meio Ambiente } \\
\text { - PNUMA". }\end{array}$ & $\begin{array}{l}\text { Profissionais da administração pública do Território } \\
\text { Estratégico de Suape que atuam em áreas } \\
\text { correlatadas à Educação Ambiental, empresários e } \\
\text { trabalhadores das empresas instaladas dentro do } \\
\text { território de Suape, residentes de comunidades } \\
\text { instaladas dentro do território da empresa Suape, } \\
\text { recursos humanos da própria empresa Suape, } \\
\text { estudantes universitários, membros das dua } \\
\text { organizações da sociedade civil atuantes na área } \\
\text { do Complexo Industrial Portuário de Suape. }\end{array}$ \\
\hline $\begin{array}{l}\text { C2- Curso de } \\
\text { Pedagogia } \\
\text { Ambiental }\end{array}$ & $\begin{array}{l}\text { Desenvolver com educadores } \\
\text { de diversas áreas afins, a } \\
\text { discussão e a difusão de } \\
\text { conceitos e ações de } \\
\text { sustentabilidade, usando } \\
\text { instrumentos metodológicos } \\
\text { e bases teóricas, norteadas } \\
\text { pelos princípios da Educação } \\
\text { Ambiental, } \\
\text { adequações da práticando no } \\
\text { processo do ensino- } \\
\text { aprendizagem. }\end{array}$ & $\begin{array}{l}\text { Professores, gestores de escolas, graduandos de } \\
\text { cursos de licenciaturas, educadores sociais, } \\
\text { agentes de saúde e representantes de empresas } \\
\text { do setor de gestão ambiental na área de influência } \\
\text { direta e indireta de Suape. }\end{array}$ \\
\hline $\begin{array}{l}\text { C3- } \\
\text { Nascentes: } \\
\text { Educação } \\
\text { Ambiental } \\
\text { para } \\
\text { conservação } \\
\text { do nascer } \\
\text { das águas. }\end{array}$ & $\begin{array}{l}\text { Subsidiar ao público-alvo } \\
\text { conhecimentos suficientes } \\
\text { para se pensar, discutir e agir } \\
\text { de forma crítica, racional e } \\
\text { construtiva sobre a situação } \\
\text { atual dos recursos hídricos e } \\
\text { como contornar os problemas } \\
\text { relacionados às nascentes }\end{array}$ & $\begin{array}{l}\text { Residentes dos oito municípios do Território } \\
\text { Estratégico de Suape e que sejam: estudantes ou } \\
\text { profissionais nas áreas das Ciências Naturais, } \\
\text { Ciências Biológicas, Ciências Ambientais, da } \\
\text { Pedagogia, das licenciaturas em geral; que sejam } \\
\text { servidores públicos ou que trabalhem em Suape ou } \\
\text { em empresas instaladas no território da empresa } \\
\text { Suape. }\end{array}$ \\
\hline $\begin{array}{l}\text { C4 - Curso } \\
\text { de Gestão de } \\
\text { Resíduos } \\
\text { Sólidos- } \\
\text { experiência } \\
\text { Suape }\end{array}$ & $\begin{array}{l}\text { Capacitar e mobilizar os } \\
\text { diversos atores sociais para } \\
\text { implantação e monitoramento } \\
\text { da Coleta Seletiva, } \\
\text { proporcionando } \\
\text { conhecimentos ecológicos, } \\
\text { legais, técnicos e } \\
\text { socioambientais sobre } \\
\text { processo de gestão dos } \\
\text { resíduos sólidos sendo } \\
\text { domiciliar ou empresarial. }\end{array}$ & $\begin{array}{l}\text { Profissionais da administração pública dos } \\
\text { municípios do Território Estratégico de Suape que } \\
\text { atuam em áreas correlatadas à Gestão Ambiental, } \\
\text { empresários e trabalhadores das empresas } \\
\text { instaladas no Complexo Industrial Portuário de } \\
\text { Suape, pessoas da comunidade local residente no } \\
\text { território de Suape, recursos humanos da própria } \\
\text { empresa, estudantes universitários, membros das } \\
\text { organizações da sociedade civil atuantes na área } \\
\text { do Complexo Industrial Portuário de Suape e } \\
\text { residentes no Território Estratégico de Suape. }\end{array}$ \\
\hline $\begin{array}{l}\text { O5- Oficina } \\
\text { de } \\
\text { Restauração } \\
\text { Florestal - } \\
\text { Mata } \\
\text { Atlântica }\end{array}$ & $\begin{array}{l}\text { Sensibilizar atores sociais por } \\
\text { meio de produção de } \\
\text { conhecimento bem como } \\
\text { práticas vivenciais voltadas a } \\
\text { produção de mudas de } \\
\text { espécies nativas da Mata } \\
\text { Atlântica, no Complexo }\end{array}$ & $\begin{array}{l}\text { Destina-se a comunidades das regiões } \\
\text { circunvizinhas de Suape, estudantes universitários, } \\
\text { profissionais das áreas afins, pessoas envolvidas } \\
\text { com processos de restauração florestal. }\end{array}$ \\
\hline
\end{tabular}

Fonte: Projeto Pedagogia Ambiental, 2019.

As capacitações são destinadas prioritariamente para pessoas acima de 18 anos de idade, com ensino médio completo e residentes em municípios 
dentro do Território Estratégico de Suape e atendem pessoas que não fazem parte dos seus respectivos públicos-alvo, mas essa não é a regra. Para demonstração ilustrativa, segue o mapa do Território Estratégico de Suape contido na Figura 1.

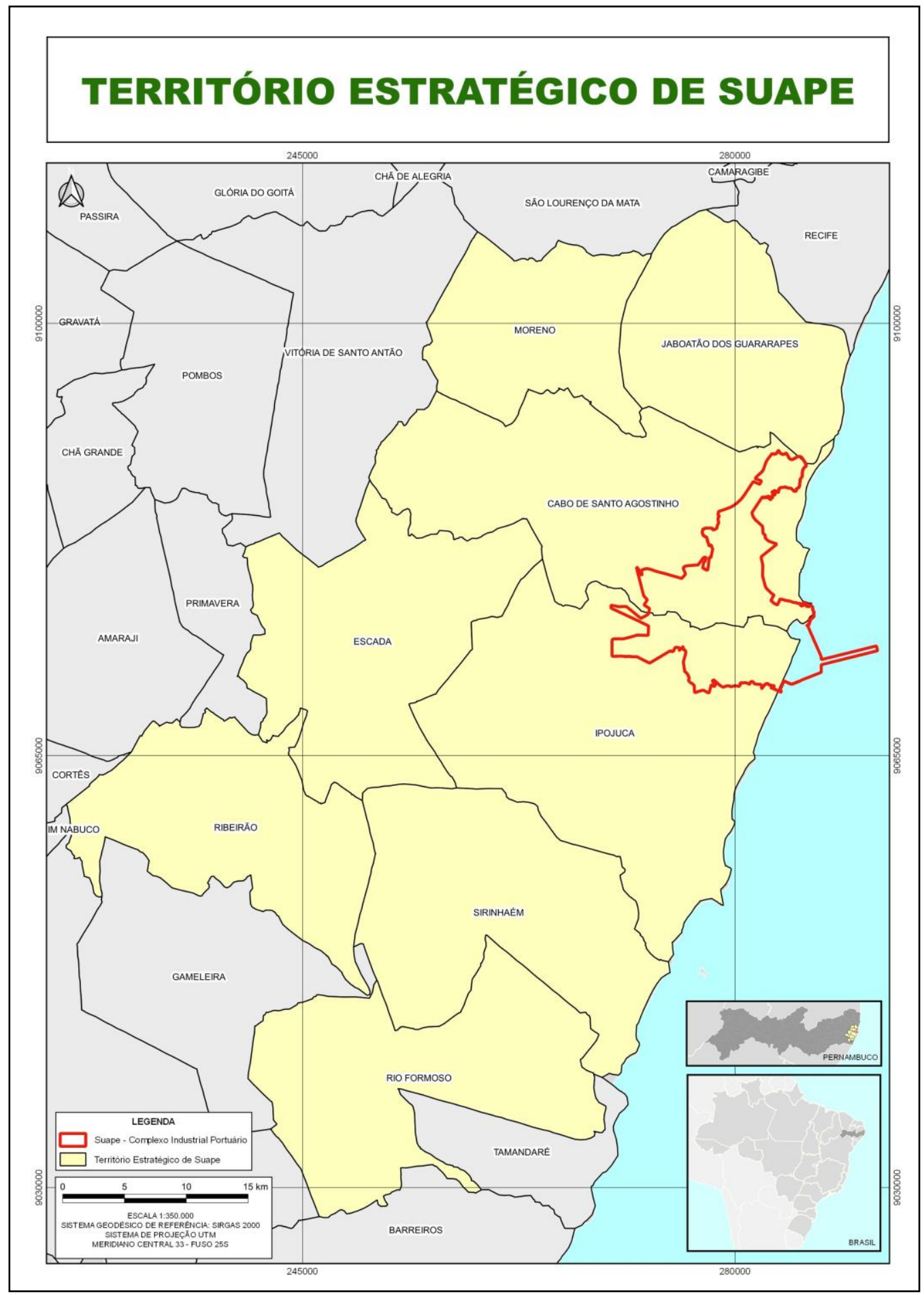

Figura 1: Território Estratégico de Suape.

Fonte: Coordenadoria de Informações Territoriais, Diretoria de Gestão e Planejamento, Suape.

Revbea, São Paulo, V. 17, № 1: 315-334, 2022.

revista brasileira educação ambiental 
Todas as capacitações possuem formatos muito semelhantes, com carga horária total de 40 horas-aulas, sendo divididas em cinco módulos com oito horas-aulas. É fornecido transporte de ida e volta entre os centros das cidades de Ipojuca e Cabo de Santo Agostinho e o Centro de Treinamento de Suape. Também é fornecido desjejum e almoço. As aulas são expositivas tradicionais, expositivas-participativas, em sala de aula, em campo e em visitas técnicas.

O Projeto Pedagogia Ambiental de Suape oferece capacitações voltadas para o conhecimento do desenvolvimento econômico, à produção e difusão de tecnologias e conhecimentos na área socioambiental, além do retorno socioambiental decorrente do PEA. Nesse sentido, há diversos desafios para se obter sucesso no processo como desenvolver ações que promovam discussões construtivas para o aprimoramento das condições socioambientais, de áreas diversas e prioridades comuns e como conseguir que os alunos participantes das capacitações consigam executar atividades práticas que repliquem os conhecimentos adquiridos nas capacitações.

Com a promoção das capacitações ofertadas por Suape, foi criado o Plano de Monitoramento e Avaliação do Projeto Pedagogia Ambiental. A pesquisa para a definição da técnica adotada no processo de monitoramento e avaliação tem caráter exploratório, perceptivo, investigativo, sendo baseada em referências bibliográficas sobre o tema, em que se pode trabalhar uma metodologia consistente para evolução do PPA, fundamentada no Relatório Anual de 2017 - Projeto Pedagogia Ambiental. Para tanto, a metodologia de estudo teve como base a utilização de técnicas qualitativas e quantitativas para posterior processamento e análise dos resultados, tendo como principal fonte de informação os estudantes que participaram do PPA. A formulação do objeto é a pergunta referencial que guia todo o processo de planejamento da avaliação, sendo estabelecida como o primeiro passo metodológico. Os resultados obtidos do Projeto de Pedagogia Ambiental estruturados em cursos e oficinas de Educação Ambiental foram considerados os objetos de avaliação. Nesse sentido, uma pergunta norteadora foi levantada para direcionar o processo de avaliação, a saber: Que impactos de resultados já podem ser vislumbrados sobre as práticas socioambientais dos alunos?

A partir do planejamento das ações do PPA, foi proposto, desde 2010, a sistematização de uma metodologia demostrando a inclusão e uso de indicadores de desempenho para os cursos e oficinas ministrados, sob a luz dos resultados obtidos, como também, o levantamento das práticas socioambientais realizadas pelos alunos por meio de aplicação de questionário devolvidos na metodologia.

$O$ indicador elaborado para ser adotado no processo de monitoramento e avaliação do PPA foi o da Replicabilidade, que indica o perfil das práticas socioambientais realizadas pelos alunos relacionadas à aplicação de conhecimentos produzidos e adquiridos durante os cursos e oficinas. 
Conectado ao indicador foi estabelecido o seu verificador, que segundo Krob et al (2009), esse deve ser facilmente compreensível e viável quanto a coleta de informações junto aos envolvidos. Conforme os autores, quanto maior a subjetividade do indicador, maior a dificuldade de medi-lo e maior o número de verificadores relativos necessários, que não é caso dessa metodologia, pois possui indicadores bastante objetivos e com verificador específico para realizar a avaliação.

Abaixo apresentamos a proposição do indicador selecionado, os meios de verificação (verificadores) e seus principais parâmetros de interpretação dos dados mensuráveis (Tabela 2).

Tabela 2: Conjunto de indicadores aplicados na avaliação do projeto.

\begin{tabular}{|c|c|c|c|}
\hline Indicadores & $\begin{array}{l}\text { O que mede ou } \\
\text { verifica }\end{array}$ & $\begin{array}{l}\text { Parâmetro de } \\
\text { interpretação }\end{array}$ & Aplicado em \\
\hline $\begin{array}{c}\text { Índice } \\
\text { Percentual de } \\
\text { Alcance de } \\
\text { Metas de } \\
\text { Resultados } \\
\text { (IA). }\end{array}$ & $\begin{array}{l}\text { A quantidade de metas de } \\
\text { resultados alcançados em } \\
\text { comparação ao que foi } \\
\text { planejado num } \\
\text { determinado período de } \\
\text { tempo. }\end{array}$ & $\begin{array}{c}\text { 0\% a } 25 \% \text { - Alcance muito baixo. } \\
25,1 \% \text { a } 50 \% \text { - Baixo Alcance. } \\
50,1 \% \text { a } 75 \% \text { - Médio Alcance. } \\
75,1 \% \text { a } 100 \% \text { - Alto Alcance. }\end{array}$ & $\begin{array}{c}\text { Metas de resultados } \\
\text { mensuráveis relacionados ao } \\
\text { número de alunos envolvidos e } \\
\text { quantidade de cursos } \\
\text { ministrados e outros resultados } \\
\text { esperados. }\end{array}$ \\
\hline $\begin{array}{l}\text { Índice de } \\
\text { Desempenho } \\
\text { Pedagógico } \\
\text { dos Cursos } \\
\text { (IDC } \text { curso). }\end{array}$ & $\begin{array}{l}\text { O nível de satisfação dos } \\
\text { alunos quanto aos } \\
\text { aspectos pedagógicos } \\
\text { aplicados nos cursos. }\end{array}$ & $\begin{array}{c}0 \text { a } 0,20 \text { - Muito baixo ou } \\
\text { inexistente. } \\
0,21 \text { a } 0,4 \text { - Baixo. } \\
0,41 \text { a } 0,6 \text { - Médio. } \\
0,61 \text { a } 0,8 \text { - Alto. } \\
0,81 \text { a } 1 \text { - Muito alto ou Excelente. }\end{array}$ & $\begin{array}{c}\text { Alunos que concluiram os } \\
\text { cursos através de pesquisa de } \\
\text { opinião. }\end{array}$ \\
\hline $\begin{array}{c}\text { Perfil de } \\
\text { atividades } \\
\text { socioambientai } \\
\text { s praticadas } \\
\text { por } \\
\text { beneficiários a } \\
\text { partir de } \\
\text { conhecimento } \\
\text { s adquiridos } \\
\text { no projeto. }\end{array}$ & $\begin{array}{l}\text { O potencial de iniciativas } \\
\text { aplicadas por alunos } \\
\text { egressos do projeto. }\end{array}$ & $\begin{array}{l}\text { A existência de experiências } \\
\text { iniciais de aplicação de } \\
\text { conhecimentos por parte dos } \\
\text { beneficiários motivadas pelo } \\
\text { projeto revela o potencial de } \\
\text { Replicabilidade dos conteúdos } \\
\text { educacionais trabalhados nas } \\
\text { oficinas e cursos de Educação } \\
\text { Ambiental. }\end{array}$ & $\begin{array}{l}\text { Alunos que concluiram os } \\
\text { cursos e que desenvolveram ou } \\
\text { fortaleceram suas práticas } \\
\text { socioambientais. }\end{array}$ \\
\hline
\end{tabular}

Fonte: Projeto Pedagogia Ambiental, 2010.

As ações realizadas pelos alunos, pós cursos e oficinas dos concluintes, são de fundamental importância para medir os conhecimentos adquiridos durante as atividades pedagógicas realizadas dentro do Projeto Pedagogia Ambiental. 
Descrição da elaboração dos projetos nos cursos e de como a Replicabilidade é feita

Construção da Matriz de Consistência em Projetos de Educação Ambiental

A análise dos resultados da aplicação dos indicadores além de fornecer elementos para avaliar o processo das capacitações do PPA, permite perceber um panorama das questões ambientais e da Educação Ambiental no Território Estratégico de Suape, sob a ótica dos participantes.

Para construção dos projetos de intervenções socioambientais ou projetos pedagógicos ambientais, o primeiro passo é possibilitar uma compreensão abrangente dos problemas e potencialidades socioambientais, por meio de dinâmica interativa no primeiro módulo das capacitações, que os discentes se apresentam e descrevem sua realidade. Daí em diante, os cursos e oficinas fornecem condições para que os alunos compreendam a complexidade estrutural e dinâmica de suas inter-relações, a problemática socioambiental contemporânea e os sistemas ambientais complexos, no intuito de durante o processo pedagógico, seja construído projeto de intervenção socioambiental ou projeto pedagógico em seu local de referência e de forma exequível. Os projetos devem ser elaborados em grupo ou individualmente, por meio da construção da matriz de consistência, que visa à sistematização das atividades a serem realizadas, seguindo o modelo proposto no Caderno do Curso Nascentes Educação Ambiental para a Conservação do Nascer das Águas, com as seguintes etapas de construção de projetos:

a) Problema (descrição do grande problema ou problema. Somente para projetos de intervenção);

b) Justificativa (dizer claramente por que o projeto é bom e deve ser realizado);

c) Beneficiários (quem vai se beneficiar diretamente com a intervenção);

d) Objetivo geral (o grande objetivo do projeto. A resolução do problema);

e) Objetivos específicos (descrição dos objetivos para cada problema menor ou nó crítico);

f) Atividades de desenvolvimento (descrição de cada atividade necessária para se atingir os objetivos específicos);

g) Recursos (descrição dos recursos humanos, materiais permanentes, de consumo, infraestrutura etc.);

h) Orçamento (previsão de quanto se gastará com o projeto);

i) Avaliação (métodos e periodicidade para avaliação dos resultados parciais e finais do projeto); 
j) Resultados esperados (descrição do que se espera obter ao término do projeto);

k) Textos consultados (referências que foram consultadas para elaboração do projeto);

I) Observações (possíveis parcerias, colaboradores, financiadores etc.).

Entretanto, antes da construção da matriz de consistência é solicitada a realização de diagnóstico socioambiental do local a ser realizado o projeto de intervenção socioambiental ou projeto pedagógico, mostrando o panorama real vislumbrando parcerias, identificando os diversos atores sociais locais e inclusive na sala de aula, os alunos também identificam profissionais ou agentes públicos que podem contribuir na execução das ações planejadas. $\mathrm{Na}$ verdade, essa é uma busca preliminar do entendimento holístico sobre a complexidade e diversidade ambiental descrita a seguir.

Segundo Medina (2001, p.12),

pensar o ambiental, hoje, significa pensar de forma prospectiva e complexa introduzir novas variáveis nas formas de conceber o mundo globalizado, a natureza, a sociedade, o conhecimento e especialmente as modalidades de relação entre os seres humanos, a fim de agir de forma solidária e fraterna, na procura de um novo modelo de desenvolvimento.

Pensando nessas novas variáveis, a matriz de consistência possibilita as atividades prévias e definições para implantação do projeto elaborado pelos alunos. É importante registrar que apenas a Oficina de Restauração Florestal Mata Atlântica não prevê em sua composição a apresentação de projeto de intervenção, embora que na Replicabilidade, na aplicação do questionário, seus alunos também apresentem resultados de ações. A não elaboração de projeto nessa capacitação ocorre por vários motivos, como: ela é uma capacitação muito sensorial, prática, dinâmica; estimula a execução de intervenções, no sentido de plantio de espécies nativas, durante todos os seus módulos; seu conteúdo programático não permite a elaboração de projeto, já que o produto final da Oficina é o plantio de espécies arbóreas de Mata Atlântica.

Após o término dos cursos e oficinas depois de quatro meses, é realizado o processo de avaliação da Replicabilidade das atividades concretizadas pelos alunos, como resultado do que foi aprendido. 


\section{Como é feita a Replicabilidade?}

Após o período de quatro meses de término dos cursos e oficinas, a equipe técnica entra em contato com os participantes por telefone, para aplicação do questionário para a Replicabilidade, utilizando as informações e indicadores através do M\&A (Monitoramento e Avaliação), que segundo kressirer et al. (1993, p. 24),

- M\&A fornece a base de informações necessárias para o gerenciamento da execução do projeto. O gerenciamento não pode ser um processo mecânico ou automático. As mudanças no ambiente do projeto devem ser consideradas, pois a equipe do projeto amplia seus conhecimentos a partir das experiências feitas, novas ideias são incorporadas ao trabalho. Neste sentido, o gerenciamento baseado na $M \& A$ deve ser entendido como um processo contínuo de discussão e aprendizado.

A partir de 2017 foi definido pela Coordenação de Educação Ambiental e Responsabilidade Socioambiental de Suape, em conjunto com a equipe técnica do Instituto Monã, qual seria o percentual de entrevistados para o levantamento da Replicabilidade; assim, ficou definido $50 \%$ do número dos concluintes por turma para identificação das práticas socioambientais.

Em 2017 o número de cursos e oficinas atenderam a 21 turmas, com representatividade de 475 alunos concluintes, já em 2018 o número de turmas atendidas foram de $19 \mathrm{com}$ resultado de 321 concluintes e em 2019 atendidas 21 turmas com 410 concluintes. Na busca de resultado da Replicabilidade são contatados $50 \%$ do total de concluintes, a execução é realizada por sorteio, de maneira a ser o mais impessoal possível, para obtenção dos dados reais. Porém, o contato com os alunos nem sempre é concretizado, o que efetivamente resultou na avaliação da Replicabilidade de 253 alunos concluintes.

A sistematização dos dados no ano de 2017 foi realizada conforme o planejamento. Já a de 2018 foi encerrada em abril de 2019, pois as últimas turmas do ano encerraram em dezembro do ano corrente. As entrevistas das turmas do ano de 2019 ficaram somente para o mês de janeiro de 2020, porque no ano anterior as capacitações começaram quase no meio do ano, então ficou definido em conformidade com a Coordenação, a aplicação dos questionários de todas as turmas em janeiro e sua sistematização em fevereiro de 2020.

No levantamento é possível saber, o curso ou oficina realizada, nome da pessoa, o que faz, o nível de escolaridade, local onde mora, faixa etária, se desenvolveu alguma prática a partir dos conhecimentos adquiridos no projeto, e se sim, qual? Senão, qual motivo? Sendo realizada, qual foi a prática? Onde está sendo aplicada? Com quem e em que fase? 
Os dados citados no parágrafo anterior são obtidos a partir de um formulário predefinido, conforme o Anexo I.

Perante os resultados levantados e obtidos foi possível avaliar e identificar as metas pretendidas e alcançadas, como também fazer ajustes necessários na metodologia adotada, condizente com a realidade do discente.

Para isso, foram utilizados os quantitativos totais de respostas para cada pergunta objetiva e as respostas foram comparadas entre si (dentro de cada pergunta) utilizando-se uma margem de erro de $3 \%$ para mais ou para menos com $98 \%$ de confiabilidade. No caso de perguntas que permitiam mais de uma resposta, para a formação da margem de erro foi considerada uma resposta dentro do universo amostral. Essas margens de erro foram calculadas conforme Alves-Mazzotti e Gewandsnajder (2000), onde:

$\mathrm{ME}=0,98$ vezes raiz quadrada de $[(\mathrm{N}-\mathrm{n}) /(\mathrm{Nn}-\mathrm{n})]$.

Onde $\mathrm{ME}$ igual à margem de erro, $\mathrm{N}$ corresponde ao universo amostral $\mathrm{e}$ $\mathrm{n}$ ao tamanho da amostra das entrevistas. Logo:

$\mathrm{ME}=0,98 \times$ raiz quadrada de $[(1173-500) /(1173 \times 500-500]$

$\mathrm{ME}=0,98 \times$ raiz quadrada de $[(672) /(103 \times 96-96)]$

$\mathrm{ME}=0,98 \times$ raiz quadrada de $[(672) /(582000)]$

$\mathrm{ME}=0,98 \times$ raiz quadrada de 0,001148

$\mathrm{ME}=0,98 \times 0,033899$

$\mathrm{ME}=0,033211$

$\mathrm{ME}=3 \%$ para mais ou para menos (arredondado).

\section{Replicabilidade em Foco}

A fim de realizar uma análise dos Resultados da Replicabilidade do PPA como métodos para avaliação e base para tomadas de decisões, foram considerados sete itens a serem apresentados.

Desse modo, os itens selecionados pela sua relação com a metodologia aplicada foram: Que capacitação foi realizada pelo aluno que fez Replicabilidade? Quais os municípios foram desenvolvidos as ações? Se os alunos desenvolveram alguma prática e os alunos que não desenvolveram? Qual a dificuldade encontrada para a não realização? Qual a temática trabalhada na execução? Onde está sendo aplicada a ação? O público-alvo a ser atendido com a ação?

A Replicabilidade dos alunos que concluíram os cursos e oficina ofertados pelo Projeto Pedagogia Ambiental demostrado na Figura 2, tem em Oficina de Restauração Florestal 43 alunos entrevistados, no de Nascentes foram 27, já no Livre de Educação Ambiental tivemos 37, em Pedagogia Ambiental o quantitativo de 58 e, por fim, o Curso de Gestão dos Resíduos Sólidos tiveram 88 alunos entrevistados. O quantitativo se apresenta de forma díspar, devido à procura maior em determinado curso pela atratividade da temática ofertada, no qual foi garantido maior público no Curso de Gestão de Resíduos Sólidos. Nesse sentido, foi observado que a grande demanda está 
associada a excessiva quantidade de resíduos existentes nas comunidades por não ter uma gestão correta de destinação adequada dos próprios alunos.

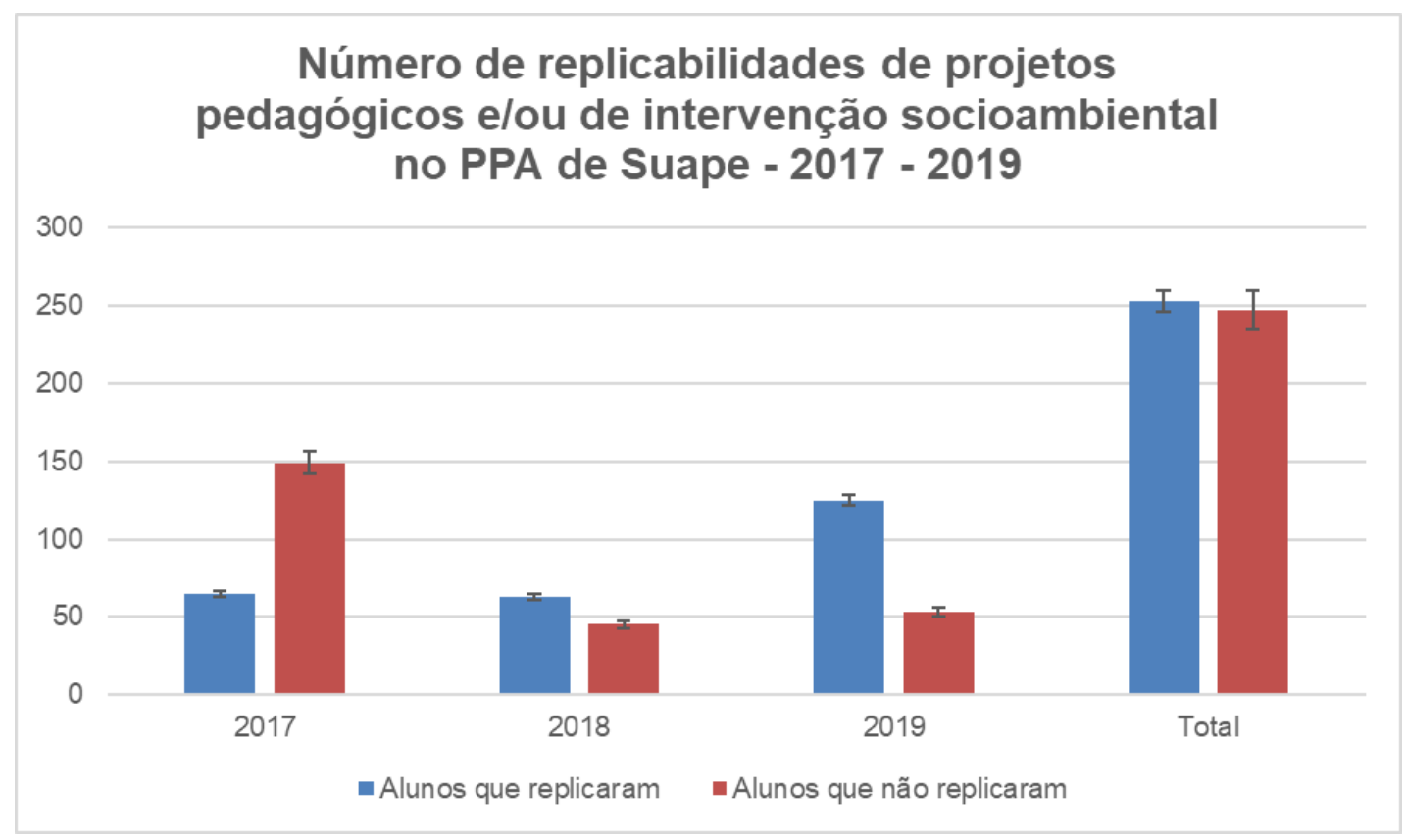

Figura 2: Quantitativo em números absolutos de alunos participantes das capacitações do Projeto Pedagogia Ambiental de Suape (PPA) que desenvolveram projetos

Fonte: Projeto Pedagogia Ambiental, 2019.

A Figura 3 apresenta os municípios em que ocorreram as ações de Replicabilidade. Deve-se um destaque ao município do Cabo de Santo Agostinho, além de ser participante do Território Estratégico, é área de influência direta de Suape, bem como Ipojuca. O primeiro com maior representatividade com índice de $19,37 \%$ é o Cabo de Santo Agostinho. Vale registrar que outros municípios do Território Estratégico também desenvolveram atividades, embora com índices menores, como os municípios de Escada, Rio Formoso e Ribeirão, que ficaram na categoria outros.

Dos que não conseguiram replicar, várias foram as dificuldades relatadas, algumas inclusive não estavam contidas no Questionário da Replicabilidade e que foram categorizadas como outros. Tais dificuldades abrangem casos como doenças, falta de recursos, tempo disponível e fatores externos, somando $37,10 \%$ da não execução, como apresentado na Figura 4. Também merecem destaque aqueles que afirmaram não conseguirem realizar seus projetos por não estarem trabalhando. 


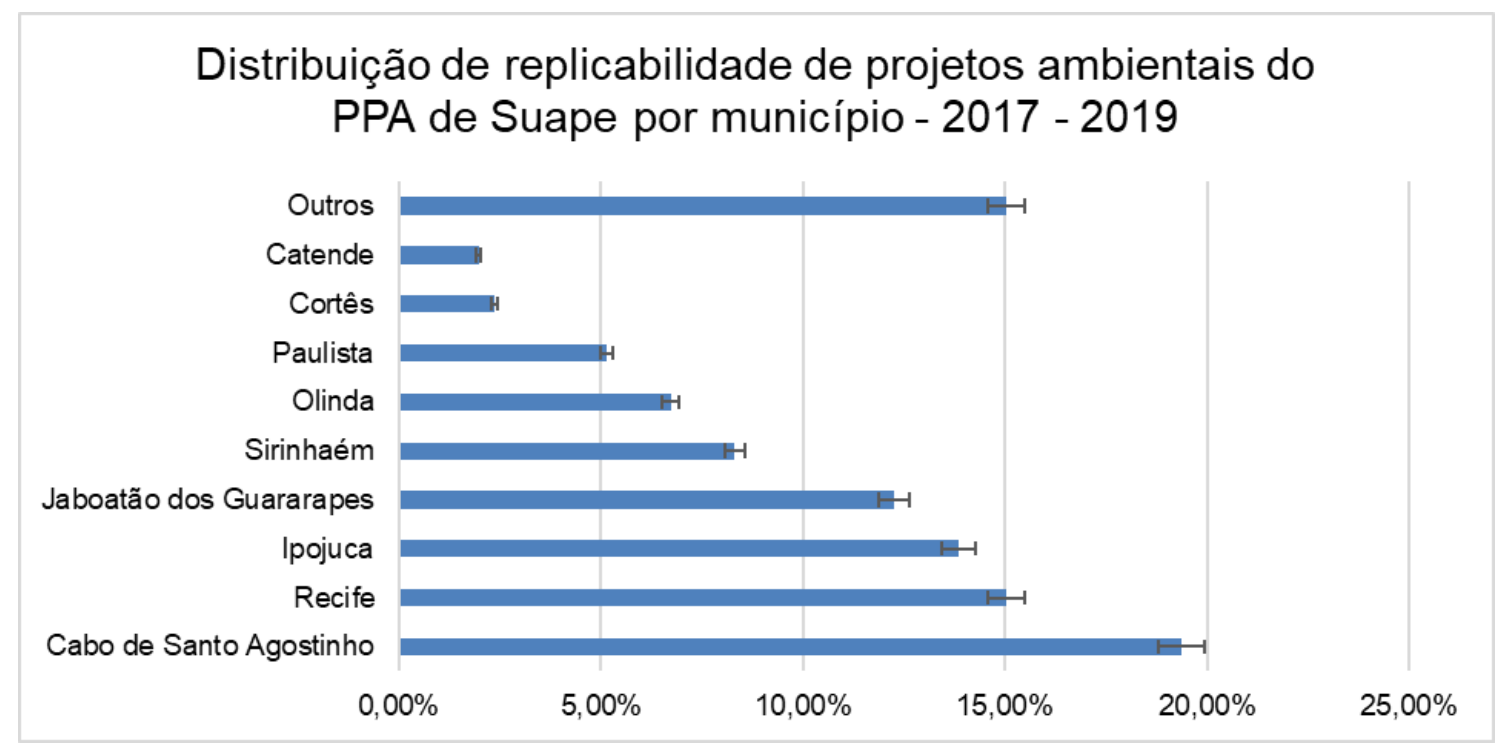

Figura 3: Replicabilidade evidenciada no Projeto Pedagogia Ambiental de Suape (PPA) por município de Pernambuco, Nordeste do Brasil.

Fonte: Projeto Pedagogia Ambiental, 2019.

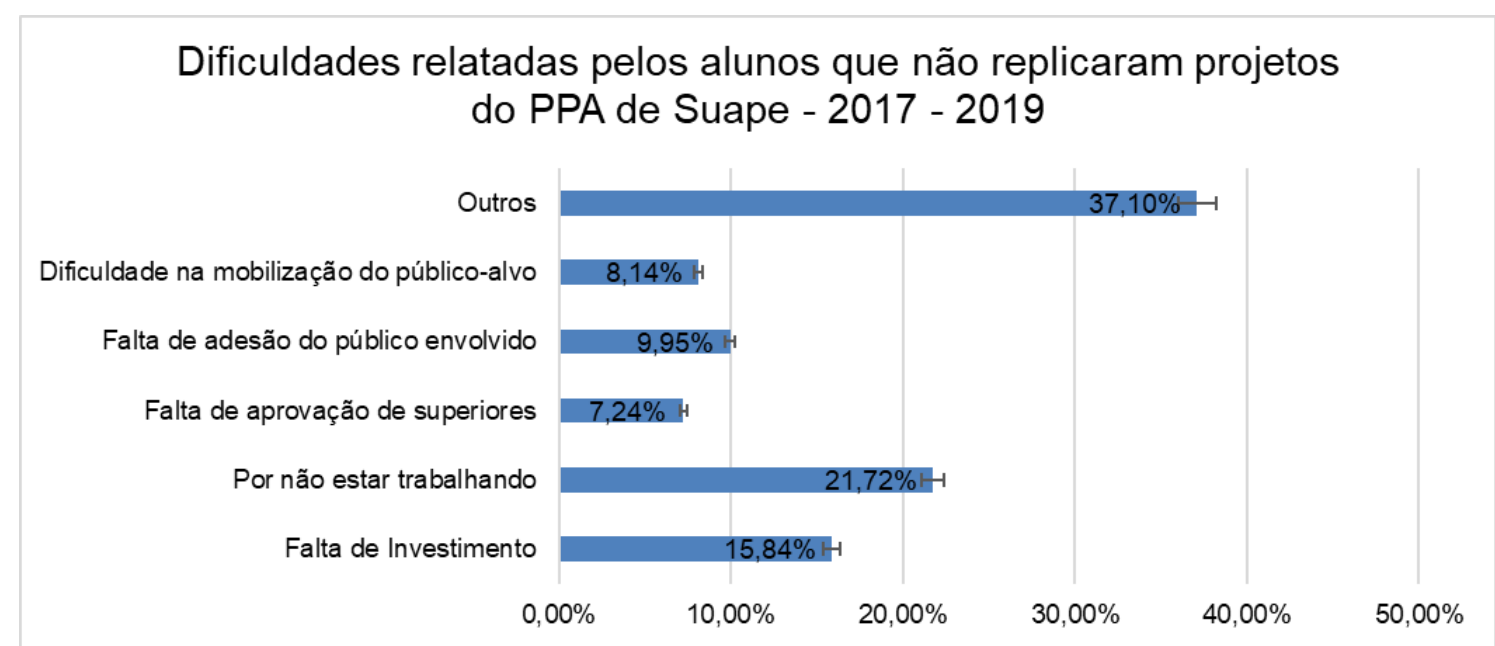

Figura 4: Dificuldades relatadas pelos alunos do Projeto Pedagogia Ambienta de Suape (PPA) que não replicaram seus projetos.

Fonte: Projeto Pedagogia Ambiental, 2019.

O Projeto Pedagogia Ambiental tem o objetivo de sensibilizar, conscientizar e mobilizar populações do Território Estratégico de Suape com a finalidade de despertar na comunidade os cuidados com o ambiente em que vivem. Sendo assim, constata-se que no ano de 2017 a quantidade de alunos que realizaram a Replicabilidade foi de apenas 65 alunos dos entrevistados, embora tenha sido o primeiro ano de retomada do Projeto. No ano seguinte, o quantitativo foi de 63 que replicaram, um valor um pouco abaixo, no entanto 2018 tenha sido um ano atípico, com paralização dos caminhoneiros no país, como também a diminuição do quantitativo de pessoas nas turmas, de 30 para 20 pessoas. Já em 2019, o ano apresentou um crescimento considerável nos resultados. É possível que com a mudança no cenário econômico, político, 
social e ambiental, no ano de 2019 sugiram oportunidades de realizações e investimentos, conforme mostra Figura 4.

O foco temático com maior abordagem na condução de realização dos projetos pedagógicos e projetos de intervenção socioambiental, foi a temática de resíduos sólidos, com $47,44 \%$ do total apresentado. Essas atividades foram desenvolvidas em rios, praias, escolas, comunidades e prefeituras. É um tema apresentado como um problema comum, independente do local onde as pessoas estejam. Os dados supracitados estão contidos na Figura 5.

\section{Replicabilidade de projetos ambientais do PPA de Suape por área temática - 2017 - 2019}

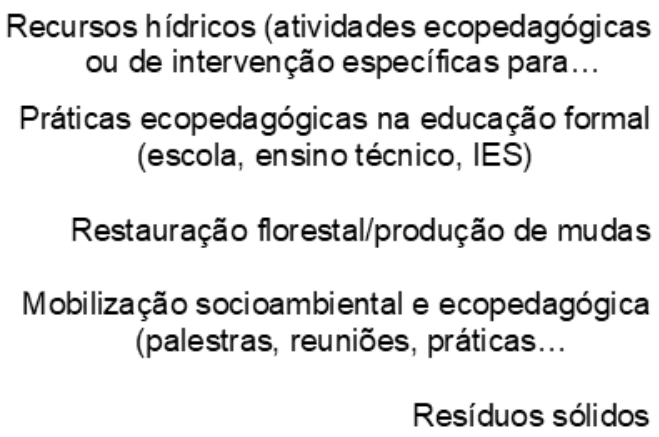

Restauração florestal/produção de mudas

Mobilização socioambiental e ecopedagógica (palestras, reuniões, práticas...

Resíduos sólidos

Figura 5: Foco Temático da Replicabilidade realizada por alunos das capacitações do Projeto Pedagogia Ambiental de Suape (PPA).

Fonte: Projeto Pedagogia Ambiental, 2019.

Na Figura 6, são evidenciadas as quatro principais categorias de locais onde houve a aplicação da Replicabilidade, como: Instituições de Ensino Fundamental II, Instituições de Ensino Médio, Instituições de Ensino Público Federal e Instituições de Ensino Superior.

É notório que o local mais escolhido pelos alunos que replicaram seus projetos foi a comunidade onde residem. É muito possível que esses dados demonstrem a magnitude da comunidade como local mais escolhido por causa da acessibilidade ser mais fácil.

$\mathrm{Na}$ construção da Matriz de Consistência, na elaboração dos Projetos Pedagógicos e Projetos de Intervenção Socioambiental, os alunos já visualizam o público que irão atender, a sociedade (comunidade) aparece aqui como o de maior índice, ela se destaca pelo grau de importância dada aos participantes, sejam eles gestores públicos, gestores escolares, estudantes, funcionários de empresas, representantes da sociedade civil. 


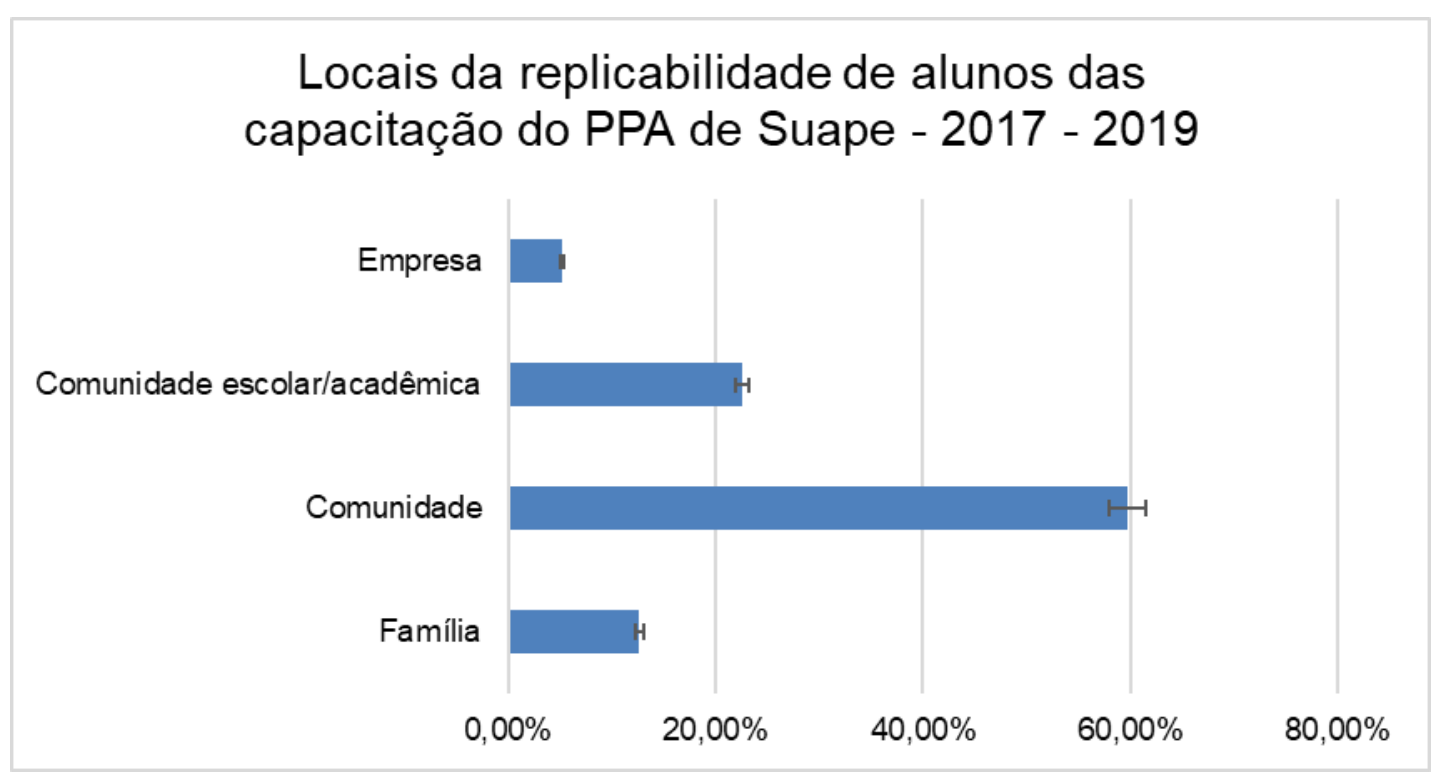

Figura 6: Locais onde foram executados projeto elaborados no Projeto Pedagogia Ambiental de Suape (PPA).

Fonte: Projeto Pedagogia Ambiental, 2019.

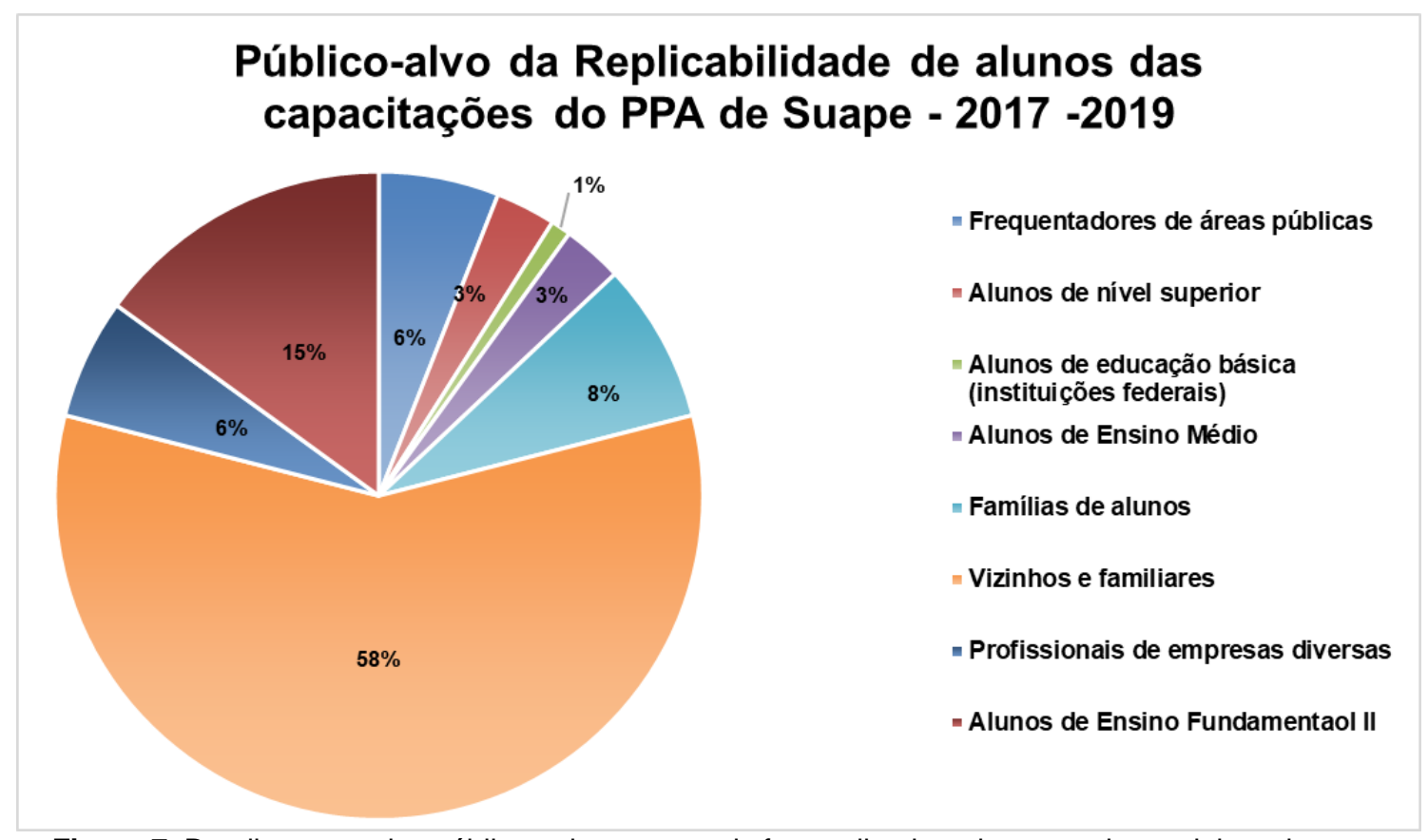

Figura 7: Detalhamento dos públicos-alvo para quais foram direcionados os projetos elaborados nas capacitações do Projeto Pedagogia Ambiental de Suape (PPA). Não foi aplicada a mesma metodologia estatística que nos demais gráficos.

Fonte: Projeto Pedagogia Ambiental, 2019.

\section{Considerações Finais}

A Replicabilidade juntamente com a elaboração de projetos ambientais nas capacitações tem sido um parâmetro considerado excelente para a avaliação do PPA de Suape e sua promoção de agentes (ex-alunos) que 
promovem a Educação Ambiental e intervenções socioambientais além dos limites da empresa Suape.

A Replicabilidade juntamente como os demais índices apresentados, possibilita o planejamento, adequação e direcionamento de esforços pedagógicos e práticos na execução das capacitações do PPA de Suape.

Como pode ser notado, com a Replicabilidade, pode-se visualizar quais os temas mais abordados, públicos-alvo e principalmente dificuldades encontradas pelos alunos. O que deve ser motivador para reflexões no intuito de formar agentes atuantes, expandir possibilidades de atuações e colaborar no enfrentamento de possíveis dificuldades que os alunos enfrentarão no momento de execução dos seus projetos ambientais, potencializando assim a efetividade dos agentes multiplicadores que a Educação Ambiental, de uma forma geral, tem como premissa.

Outro ponto importante e que deve ser considerado nos próximos anos de execução do PPA e avaliação por Replicabilidade é a expansão da pesquisa para o fornecimento de maiores subsídios metodológicos para o PPA, como: a faixa etária dos executores, se residem em zonas rurais ou urbanas, se foi obtido financiamento ou patrocínio, entre outros aspectos.

Por fim, é enfaticamente reforçado aqui, que outros projetos de Educação Ambiental podem fazer uso das duas ferramentas primordialmente trabalhadas neste trabalho (elaboração de projetos ambientais por alunos e Replicabilidade), como forma de mudança intelectual dos seus alunos e ambiental da sociedade.

\section{Agradecimentos}

Ao Professor José Roberto de Carvalho Zaponi, pela elaboração e efetivação do Projeto Pedagogia Ambiental de 2010 a 2016; ao Instituto Monã, pela execução do PPA de Suape entre 2017 e 2020 com excelência; à Coordenadoria de Proteção Patrimonial, à Coordenadoria de Desenvolvimento Ambiental e Sustentabilidade e ao Setor de Transporte de Suape, pelo apoio institucional de gestores e técnicos; à empresa Empesa, em nome do Senhor Gerson Batista, pela contribuição no Curso de Gestão de Resíduos Sólidos - a Experiência de Suape; ao Viveiro Florestal de Suape, na pessoa do Senhor Gerson Izidoro, pelo apoio rotineiro ao PPA de Suape; às técnicas Gláucia Rosa e Janaína Lira, pela contribuição direta ao Projeto Pedagogia Ambiental de Suape; aos estagiários da Coordenadoria de Educação Ambiental e Resíduos Sólidos de Suape, Cybelle Gadêlha, Fabiana Maria da Silva, Rafael Almeida, Rayssa Alves, Tainá Coelho e Vitória Aguiar, pelas contribuições ao Projeto; à Presidência de Suape, Diretoria de Meio Ambiente e Sustentabilidade e à Coordenadoria de Educação Ambiental e Resíduos Sólidos de Suape, em nome do Senhor Leonardo Cerquinho, Carlos Cavalcanti e Guilherme Mota, respectivamente, pelo apoio institucional, gestão profissional, disponibilização de dados e custeio da publicação. 


\section{Referências}

ALVES-MAZZOTTI, A. J; GEWANDSNAJDER, F. O. Método nas Ciências Naturais e Sociais. Pesquisa quantitativa e qualitativa. São Paulo, SP: Pioneira, 2000.

KRESSIRER, R.; SALZER, W. Monitoria e Avaliação de Projetos: orientações para o trabalho em grupo. Tradução e adaptação de Markus Brose. Deustsche Gesellschaft fur Technische.GTZ. Recife, 1993.

KROB, A.J.D.; BOHRER, P.V.; ZANK, S.; WITT, R.C.V.. O monitoramento de resultados da Educação Ambiental como estratégia para sua inclusão em políticas públicas e ações institucionais. 2009. Disponível em: $<$ http://pwweb2.procempa.com.br/pmpa/prefpoa/curicaca/usu doc/trab gongea monitoramento.pdf>. Acesso 13 de abril de 2020.

PERNAMBUCO. Decreto no 37.160, de 23 de setembro de 2011. Institui Plano Diretor - Suape 2030. Pernambuco, 2011.

PERNAMBUCO. Lei no 7.763, de 7 de novembro de 1978. Criação de Suape - Complexo Industrial e Portuário Governador Eraldo Gueiros. Pernambuco, 1978.

PIRES ADVOGADOS \& CONSULTORES. Ampliação e modernização do Porto de Suape: Estudo de impacto ambiental. Janeiro de 2000. Recife: SUAPE/CIPS, 2000a.

MEDINA, N.M..; SANTOS, E.C. Educaçao Ambiental: uma metodologia participativa de formação. Petropolis: Editora Vozes, 2001.

MODERNIZAÇÃO DE SUAPE. Disponível em: <https://www.suape.pe.gov.br/pt/institucional/historico-de-suape $>$. Acessado em 13 de abril de 2020.

SÁNCHEZ, L.E. Avaliação de impacto ambiental: conceitos e métodos. 2. ed. Oficina de Textos, 2013.

SUAPE - Complexo Industrial Portuário Governador Eraldo Gueiros. Relatório anual: Projeto pedagogia ambiental. Pernambuco: 2017. $161 \mathrm{p}$.

ZAPONI, J.R.C. et. al. Curso de Gestão de Resíduos Sólidos: a experiência de Suape: Caderno 5. Ipojuca, 2017.

ZAPONI, J.R.C.; SILVA, J.R.B.; OLIVEIRA, T.S. Curso Nascentes: Educação Ambiental para conservação do nascer das águas. Ipojuca, 2017.

ZAPONI, J.R.C. et.al. Oficina de Restauração Florestal: Mata Atlântica: Caderno 3. Ipojuca, 2017. 
Anexo I: Questionário da Replicabilidade.

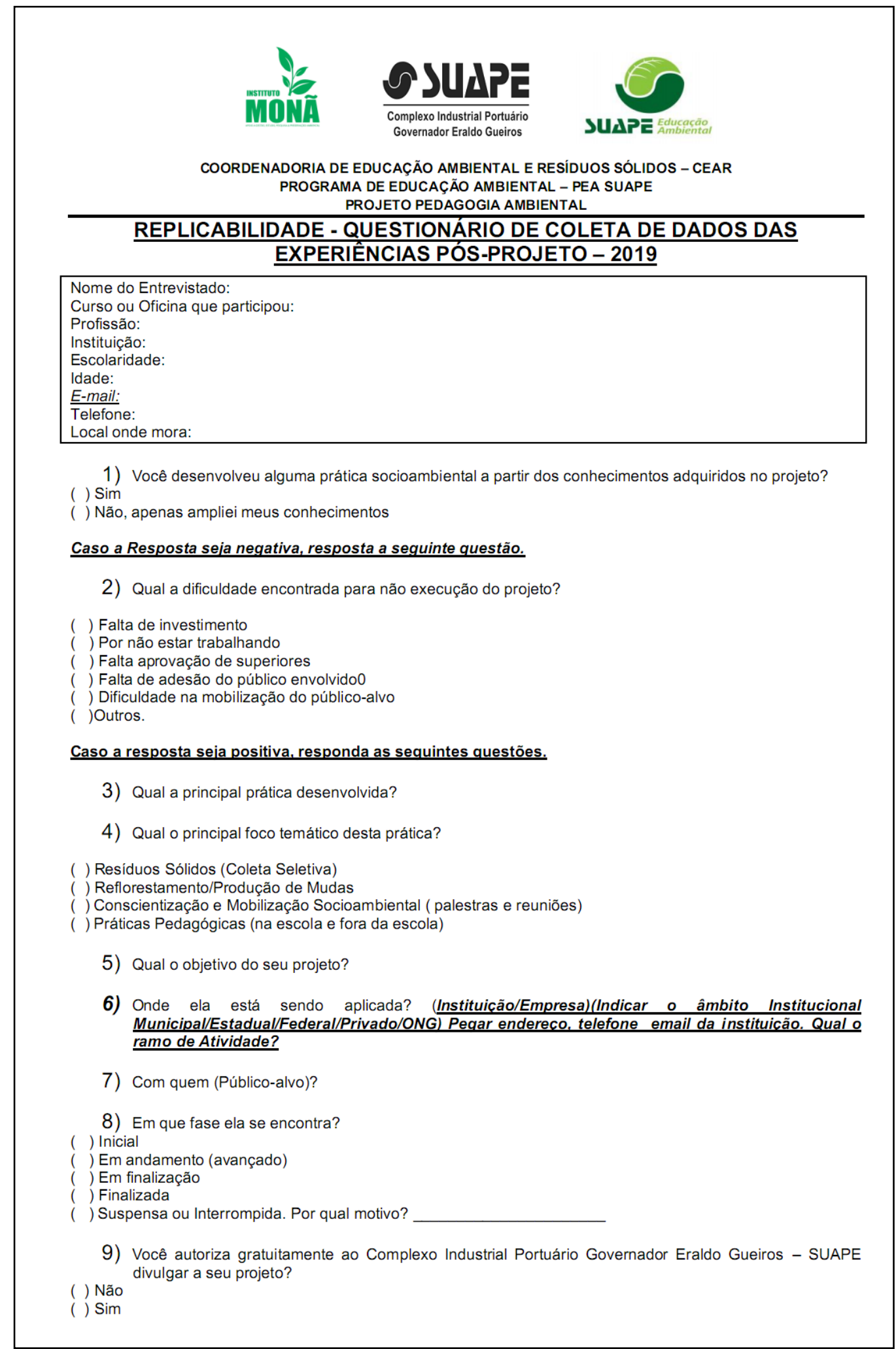

